\title{
SCHOOL ADMINISTRATORS’ DISCURSIVE POSITIONING IN TALK ABOUT DEVIANT HIGH SCHOOL STUDENTS
}

\author{
Krishna Seunarinesingh
}

\begin{abstract}
This paper presents the analysis of two school administrators' discourse whereby they relate their experiences with deviant high school students. Analysis of interview data revealed that interviewees positioned themselves as caring and inclusive educators, who understood deviant students' circumstances. They positioned students as victims of overwhelmingly negative environments, and portrayed school as a warm and welcoming space. Through this positioning strategy, they accounted for decisions not to suspend deviant students from school. The findings suggest that the administrators equated performance of caring identity with professional competence, which is a desirable membership category in educational discourses.
\end{abstract}

Keywords: Discourse analysis; Discursive positioning; School exclusion; High school deviance; Caring discourse; Inclusionary discourse; Because clause; Lexical choice.

\section{Introduction}

High school students' exclusion from school is not an issue that has attracted much attention from discourse analysts. Research into exclusion from school principally centers on psychological and sociological investigations of the phenomenon. Typically, research has examined reasons for exclusion (such as Cullingford 1999; Rosenthal and Wilson 2003; and Youngstrom Weist and Albus 2003), and the personal and social effects of the practice (Sims, Bowen and Holtom 2008).

The consensus of research findings is that the practice is unfair to certain ethnic groups, which are over-represented in the ranks of those excluded from attendance at school (Townsend 2000), it is counter-productive because it merely reinforces negative behavior (Christle, Nelson, and Jolivette 2004), and it can lead to excluded students “drifting aimlessly" and, eventually, committing crimes (Reid 2008: 88).

Excluded students can form a sub-set of a larger category of student labeled deviant, where deviance is considered a negative behavior. Heckert and Heckert (2002) offer the traditional definition of deviance as follows: "Negative deviance, the traditional focus of the sociology of deviance, refers to behaviors that involve underconformity or nonconformity to normative expectations and negative evaluations" (p. 451). In high schools, negative deviant acts can exist on a wide range. At the nonviolent end are behaviors such as truancy, stealing, gambling, and using obscene language. At the violent end are dangerous acts, such as fighting and assaulting peers 
with weapons. In the small Caribbean nation of Trinidad and Tobago, participation in negative deviant acts, such as those just described, can result in exclusion from school. This means being denied access to an institution of formal education for a period of three to seven days. Such penalty can be imposed by a school principal or vice principal, usually on the advice of senior school administrators. Longer term exclusions, called extended suspension, can last several weeks at the discretion of the Minister of Education, depending on the nature of the offence committed. Administrators' power to exclude students is contained primarily in "zero tolerance" policies: zero tolerance for acts such as violence, use of obscene language, especially to teachers, threats and violence to teachers, possession and/or use of weapons, and use of illegal substances.

However, school exclusion and zero tolerance policies have been criticized as ineffective and counterproductive (Christie, Nelson \& Jolivette 2004; Atkins et al. 2002) because they merely accelerate youths' progress along a pathway to delinquency and life-long failure, and are associated with drop-out, delinquency, and criminal behavior. Consequently, an emerging discourse in education (see maine.gov/.../DeviantPeer-Influences-Fact-Sheet.pdf; $\quad$ www.srcd.org/documents/publications/SPR/spr20 1.pdf) has begun to question the efficacy of these processes and arrangements. In its place, some authors suggest use of more classroom-based management to avoid escalating the problems (Dodge, Dishion \& Landsford 2006), as well as promotion of programs that foster deviant students' attachment to school. That is, a movement is emerging that appears to be favoring inclusionary as opposed to exclusionary policies.

The brunt of day to day management of students who are sometimes labeled deviant or 'problem children' falls upon school administrators, namely the principal, deputy principal, and deans of discipline (also called pastoral heads). This group makes immediate decisions about the consequences of deviant acts, and determines whether a student remains included or is excluded from school. Since inclusion is the ideal, but most school principals in Trinidad and Tobago exercise their right to suspend deviant students from school ${ }^{1}$, it is important to know how school administrators who deal with 'problem children', and who choose not to exclude them construct their discursive positions. Specifically, an understanding of the nature of discursive positioning that occurs in talk about "problem students" can provide insight into the underlying reasons for the administrative decisions the group of school managers make. In the specific instances treated here, the focus is on their decisions not to invoke official regulations and exclude deviant students.

The data reported on here is part of a larger project that explores classroom teachers' and school administrators' appropriation and enactment of educational discourses. The present paper focuses on aspects of appropriation of that discourse and how two administrators use it for positioning themselves, their schools, and students who commit deviant acts.

${ }^{1}$ This information was derived from Ministry of Education statistics, which showed 2651 suspensions in 2002 (the most recent report). 


\section{Methodology}

\subsection{Research context}

The high school at which this research took place exhibits administrative responses to student deviance that are atypical of schools of that type. In Trinidad and Tobago, it belongs to a group called "new sector schools" since they were built in the 1970sapproximately 50 years after traditional grammar schools. As a group, new sector schools - especially urban ones - are perceived academically as bottom-rung institutions because of the significant numbers of academically under-prepared students who attend. Also, they have the highest rates of exclusion from school via student suspension. Typically, students may be suspended for violent activity, such as fighting, or extorting money with violence; they may also be suspended for engaging in non-violent but illegal actions, such as smoking cigarettes, using obscene language, and being rude to teachers. The teachers and administrators who work in such environments are consistently identified as operating in "troubled" schools because they face issues of student management that their colleagues in traditional schools do not. At the site studied, however, students were suspended only in the most extreme cases of violence. Offences that attracted suspension at other new sector schools were dealt with without recourse to exclusion. This occurred despite the fact that school administrators had the option of invoking an official Ministry of Education policy of zero tolerance for those actions. The fact that administrators chose not to suspend deviant students, where their colleagues in similar circumstances at other schools exercised that option, provided a discursive purpose for the present research, which was to understand (a) what discourses interviewees were constructing in speaking about 'problem' students (b) what discursive positions they were adopting, and (c) what were the main linguistic strategies interviewees employed in constructing these discursive stances.

\subsection{Participants and method}

Two school administrators were interviewed: 1 . the principal and 2. a dean of discipline. At the time of the interviews, the appointed vice principal had recently retired and there was no replacement or acting vice principal in the post. The dean who participated in the study was the most senior of five who dealt with student discipline and general student welfare. He had been dean for three years when the interview took place. Prior to that, he had been a teacher of social studies. The dean was a trained teacher having undergone certification at a local university. The principal was the most experienced member of staff having held the position since the inception of the school 21 years before. He was also a trained educator and had received his teacher training from the same university as the dean. Both the principal and dean lived in communities outside of the school. Both interviewees were invited to describe and discuss their experiences of dealing with students whose actions frequently placed them at-risk of being suspended from school. Given the fact that the school they administered had an extremely low exclusion rate compared to similar ones of their type, the interviews focused on having them discuss their experiences with deviant students. Interviews were transcribed and saved as electronic documents. 
The overarching analytic method employed in this study was an eclectic one drawing from various theoretical approaches to discourse analysis, since no single way of "doing" discourse analysis exists. The method used attempted to remain true to the view that discourse analysis aims to reveal and explain what a text is doing and how it is structured to perform that function and achieve particular effects (Fairclough 2001; Gee 1999; Poggenpoel, Van Der Linde and Zeeman 2002; Wood and Kroger 2000). The basic method employed in the present study was close reading of interview transcripts in search of patterns of text organization that could lead to understanding of the research foci identified earlier.

\subsection{Conceptual frame: Positioning theory}

Classic positioning theory focuses on identities that arise in conversation. It utilizes two speech act theory concepts of propositional content and perlocutionary force in explaining the process through which positions are constituted in speech events. A position is created through a speaker's specific choice of metaphor or image. The degree to which hearers take up or accept this position determines (a) how much shifting of positions occurs in conversation and (b) the type of relationship they commit themselves to in any speech event. For example, hearers may reject speakers' propositional content because its perlocutionary effect positions them in ways they find unacceptable. In the turns that follow, each speaker attempts to gain ground and position self to advantage, whilst simultaneously positioning the other/s involved in the speech event.

Positioning theory focuses on "the process by which certain trains of consequences, intended or unintended, are set in motion” (Davies and Harré 1999: 266). These authors continue:

Positioning, as we will use it, is the discursive process whereby selves are located in conversations as observably and subjectively coherent participants in jointly produced story lines. There can be interactive positioning in which what one person says positions another. And there can be reflexive positioning in which one positions oneself.

(Davies and Harré 1999: 264)

During conversation, it is possible to reject, or resist positions whilst simultaneously attempting to position the self more advantageously. Typically, a speaker's taking up of one position forces the other speaker/s into available, sometimes opposed, positions and relations. For example, Davies and Harré describe speakers as adopting dialectically opposed positions, such as aggrieved party/ perpetrator of injustice and responsible/ irresponsible. They note that conversants thus positioned may be locked into few rhetorical possibilities for escape because of the "power of the storylines" that their words generate. Speakers' beliefs about "the sorts of persons", including themselves, who are engaged in the conversation are important for positioning theory.

The present study generated interview data, which is not the "naturally occurring" talk-in-interaction that positioning theory originally focused on. However, interviews may be seen as negotiated texts produced between interviewer and interviewee (Fontana \& Frey 2005), so that the interviewees, in this case school administrators, may be seen as taking up various subject positions in the course of producing accounts of what happens in their interactions with deviant students. In the 
process, they draw upon those categories available to them in discourses about education of "difficult children". That is, by situating themselves in specific subject positions, interviewees have access to what Davies and Harré (1999) call the "conceptual repertoire" and "rights and duties" of those positions. This study uses the frame provided by positioning theory to understand and analyze the discursive categories interviewees choose for themselves. It differs significantly from other studies of teacher positioning (such as Currie, Kelly \& Pomerantz 2007; and Søreide 2006) because it focuses explicitly on how positioning is achieved and what it is used for.

In the following section, an interview text from each interviewee is analysed. In each case, the text of the interview is presented following which detailed analysis is conducted. For each interview text, interviewer is abbreviated ' $\mathrm{I}$ '; respondent or interviewee is abbreviated ' $\mathrm{R}$ '.

\section{Results}

Text 1. Interview with the dean

1. R: So as far as the culture is concerned, with students, um, ....there are time, there are

2. times when they do get into scrapes right? But they are very quick to admit they are wrong

3. and.they are very quick to apologize. I suppose probably because suspension, if any, does not

4. really work for them because it sends them back into a little, how should I say, a cavern, a

5. cavernous space... where they have to wait a few days before they come back out and, um,

6. chance are they don't want to be in , they want to be out. Then you have those students who

7. come to school with a desired intention to provoke a

8. situation. It's not that they can't learn because as a teacher you have fourteen years..there is

9. an ability that pervades these children, but it's the friends he chooses. The friend chooses to

10. behave in a particular way, the friend doesn't care. The one who is capable and cares

11. somehow or the other slips into that hole..I think it has a whole lot to do with peer group

12. acceptance. It has a lot, a lot to do with peer group acceptance, right? Where at the same

13. point in time too you also have the student who is....unconcerned, totally unconcerned, just

14. couldn't be bothered. That is the person I mentioned a while ago-I rambled a little bit- but,

15. but that is the person is coming to provoke a situation, right? Because in the first instance,

16. one wonders whether that child wanted to come at all..um, I have experienced over the years

17. instances when children like these led me to wonder whether they were sent forcefully or

18. whether..they were sent... with a particular desire in mind, you see. A desire of their own,

19. right? Children cannot be fooled that easily. Children read into a situation very quickly so

20. when I , who is sent for you to care for me, come and I meet Tom, who has been sent on the

21. same basis. You could imagine what ten or fifteen of us could do? How much havoc we

22. could create. How many problems we could give in school? Because our basic objective is

23. not to take on school work at all. You see what I'm saying?

24. I: Ok. So these children come here without an academic agenda. When they come here to the

25. school, what do they encounter? What does the existing culture tell them?

26. R: all right. Um, before I track into that area, um, I was going to say, um, amongst these

27. students also are what you call the ' $S$ '2 students, who, they not really with it but,... when they

28. come into the school they meet a culture of learning, right? And if I may go so far as to say,

29. just yesterday a parent called to tell us about a child who is doing ' $A$ ' $\mathrm{s}^{3}$ and she is so

30. overwhelmed and so happy that he child went to school here. All that you hear, all that

31. people have to say about the junior secondary.. um, she called to express her utmost gratitude.

\footnotetext{
2 ' $\mathrm{S}$ ' is a widely used abbreviation for "special class”. In new sector schools, it refers to classes of children with mild to severe literacy problems.

${ }^{3}$ An advanced proficiency examination.
} 
32. She wants people to come to the junior secondary because it is not as bad as people make it 33. out to be. The culture they meet here is a culture of learning. There is a willingness, right? To 34. want to help among teachers and you find within a certain percentage of the students a 35. willingness to want to achieve something, right? Um, when you come in to the kind of 36. students who couldn't be bothered, right? That student, the student you asked me about, 37. what do they meet with when they come here? That student meets a force to be reckoned with

38. and um, there is accommodation, there is room for them. Room was created for them. It's 39. not like "okay we don't need you we don’t want you. You turn back.” Room is created for 40. them. Space is made. There is a gap open so that they may come in and fit in gracefully and 41. relate with others. What I do is I break my class into groups so that such a child could fit into 42. a group and get assistance from members of the group. Sometimes it works; sometimes it 43. doesn't work. And then, too, when I tell you about creating a space for them, I don't just 44. mean a physical space, or an academic space. I try to create a psychological space. I try to 45. generate a medium whereby the student will come to me. I think the survivors don't find 46. themselves in trouble. It's those who just not cutting it. You know, when you work on a 47. person and work on a person and you may get fed up, but you're still willing to work.

48. I: What do you talk about?

49. R: the importance of getting an education regardless of how low their circumstances may 50. appear to be. You use your experience as a teacher to get them to understand a few things 51. because, um, students need to be, um, ....students when they are told about other people's

52. experiences, students are shocked to realize that human beings all have problems , right? I go 53. into my own personal experiences and sometimes they sit looking at me with their mouths 54. open wide. I tell them about things I used to do when I was going to school. I tell them what 55. I have been able to achieve here. I'm trying to help you which means somebody helped me 56. so I can pass it on to you. They like that. That is a line I always use and they love it. It 57. means something to them. It tells them that there is somebody who cares, right. Because

58. remember they maybe coming from a home where the care is there, but the care is not

59. visible. Students appreciate whatever little you show to them. They relax, they are

60. comfortable, they try their best. But, it doesn't take away all the work you have done. Does

61. not take away from the fact that at the flick of a finger everything can go away.

62. I: Why?

63. R: Because, um, when they come here they spend five hours and relate on a particular basis 64. during the day. But, they are back into their house for the next seventeen hours. Their house 65. environment, right? I used to say the home has seventeen hours. I use to take away I hour 66. coming to school and I hour going back home. Added to five that is seven. I say the home 67. has seventeen hours. We are outweighed. So we are putting up a struggle, right? In a hope 68. against hope situation.When form teachers don't perform their jobs, my job becomes very 69.difficult. Sometimes these children go astray. They ask me, "Sir no body taking we on. Them 70. children in the class makin' noise and I will get the blame.” Because I may have a particular 71. manner about me and I may be trying , but I will still get the blame because I have been, what

72. do you call that, pin-pointed? I have been marked? Um, such a child is likely to find him or 73. herself in the office with a great deal of regularity, especially if he or she does not want to

74. listen. It's now up to the administration to see how best they can help that child's situation. 75. Sometimeswhat I do, it comes under the heading suspension, but I choose to request that your

76. parents keep you at home for a few days and talk with you in the hope that you will learn a 77. few things. Something will stick.

78. I: How does that work?

79. R: Well, according to the parents, it helps. But, there is an additional problem. When the 80. child mixes with the peer group members that child is likely to forget entirely what energies 81. you put out on him or her, um, that child is likely to forget what he/she is supposed to be here

82. for.

83. I: Is it that you try and try and call the parents to keep them for a few days? 84. R: No. You would, um, depending on how you see things going along the way the 85. suspension thing comes as an extreme. You have a lot of opportunities available to you to 
86. hold dialogue with the student. You have a lot of opportunities available to you to have 87. dialogue with the parent. And, at the end of the day, if you not getting anywhere, you could 88. offer the parent the opportunity to keep your child home for a few days, especially if it's a 89. situation like the end of school. That child is likely to get in trouble with others. To add 90. insult to injury, you have criminal acts and you want to keep the child away from that kind of 91. thing. You can require that the parent keep the child away for a few days, that kind of thing. 92. It's everybody embarrassing and disrupting everybody out there. This is why the children do 93. it. It's why the children come with it. Children come with the concept of embarrassment and 94. disrespect because is what they live in the home. You get up in the morning as a child and 95. you come outside to have breakfast and your mother cussing somebody by the back door. So 96. the whole day she will go on with that "and what they feel it is" and neglect the idea of 97. feeding you. The children learn what they live, right? And teachers now. As teachers we 98. want to help, you know. I know for a fact that there is so much you could do.

In text 1 , the dean's core argument is that suspension is a last resort that culminates a process of failed rehabilitative work. That is, the act is rare, and when it does come, it is deliberate. To convey this core proposition, the speaker positions two "objects": 1. students and their backgrounds, and 2. himself as dean. The analysis that follows examines how each of these is achieved.

\subsection{Positioning students and self}

The dean identifies two categories of students: 1 . Those who commit occasional acts of deviance, and 2. Provocateurs, who apparently commit offences more frequently because their intention is to create "havoc" in school. In order to fit them into these subjective categories, the speaker organizes his narrative in lines 3-5 around three because clauses. First, he uses it to justify not suspending the occasional deviant who is later apologetic. Here the justificatory force of because derives some of its strength from the metaphor of retreating into "a cave, a cavernous space" that succeeds it. It is unclear whether this metaphor refers to the child's home, or to a mental state where social contact is missing. However, the proposition presented in the clause is that suspension has undesirable consequences for this category of deviant.

Second, the dean uses because clauses to position those students whom he describes as "unconcerned", and whom he says deliberately set out to disrupt school. This occupies the greatest share of the interview, and is divided into two parts. First, he portrays them as possessing negative attitudes and dispositions; second, he presents them as products of overwhelmingly negative backgrounds. Three because clauses ("Because in the first instance.."; "Because our basic objective...”, and "Because I may have a particular manner about me...") attempt to establish a causal connection between (a) students' forcible attendance at school and (b) their "manner" on the one hand and their participation in deviant acts on the other. Even within this sub-category, distinctions exist: the deviant actions of those forcibly sent to school (provocateurs) are described as "havoc"; occasionally deviant students' actions are called "scrapes". To buttress this subjective judgment he relies upon claims of prior experience, which appear thrice in the text: "because as a teacher you have fourteen years", "I have experienced over the years", and "You use your experience as a teacher...". In these lines then the children's negative attitudes and dispositions to school are presented less as the speaker's perception and more as recurring episodes he has actually experienced, 
and this experience has indicated to him that it is the students who have no desire to be at school that create "havoc".

Having presented some deviant students as deliberately provocative, and therefore likely to get embroiled in trouble, the dean attempts to establish another causal relationship. Through use of the following because clauses, he attempts to correlate ineffective parenting, student deviance at school, and school's inability to make positive impact on behavior.

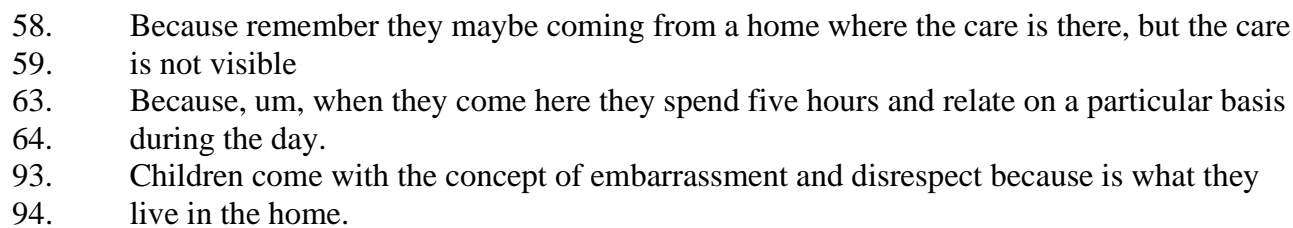

His argument is framed in terms of school being overwhelmed by the force of negative home influence. Even as he accounts for the school's relative inability to reduce deviance, his correlations suggest he is also engaging in blame-shifting for them by showing how deep-rooted is the negative conditioning they experience. This is achieved through a meronymic cluster centering on the phrase, "What they live in the home". Its immediate meronyms are "concept of embarrassment”, "disrespect”, and "care is not visible". The implication invoked here is a traditional, deterministic one: students are products of their environment. Lines 63-64 have no obvious negative comment, but derive negativity from the wider contrast of relating "on a particular basis" in school on the one hand to what the dean says occurs in "their house environment" on the other. This contrast is an important one, since it appears to pit what students experience at home with what the school (as a synecdoche for teachers) offers during the day.

After he categorizes some students as provocative, the dean is asked to describe what culture they encounter when they enter the school ${ }^{4}$. He explains that they experience a "culture of learning". This explanation can be divided into 2 "movements" or segments based on his (a) positioning of the school and (b) positioning of himself.

The first movement, in which positioning of school occurs, is brief. It comprises what the speaker himself classifies as a digression, ("before I track into that area”), but which is actually a testimonial from a parent about the school's good character. The point of the dean's anecdote about the parent's telephone call comes in the clinching statement, "because it (the school) is not as bad as people make it out to be". That is, he draws a causal connection between the parent's expression of gratitude and her satisfaction with the school on the one hand and the on-going efforts of staff to provide a "culture of learning" on the other. This proffered causal relation is the only one in the text that does not refer specifically to deviant students.

In the second movement, the speaker, whilst still describing the culture students meet when they enter the school, focuses specifically on his own actions. He offers these as characteristic of the school's approach to students. The speaker attempts to portray the school as possessing a culture of caring by presenting himself as an interested, caring and zealous friend of students. To effect this portrayal, he (a) nominalizes accommodation (L. 38) and associates with it meronyms of space-creation,

\footnotetext{
${ }^{4}$ School culture research (for example, DeWit et al. 2000) indicates that cultures in a school may have an influence on student deviance, especially where students feel unfairly treated in an "unfavorable culture”.
} 
and (b) makes lexical choices that laud the school whilst simultaneously positioning home environments negatively. Accommodation (in the declaration, "there is accommodation, there is room for them. Room was created for them.”) conveys processes of making the classroom friendly and this is buttressed through the following meronyms:

Room is created

Space is made.

There is a gap open

Come in and fit in

Break my class into groups

These phrases define accommodation in visual terms. They describe vigorous inclusion of students whom the dean implies would be otherwise marginalized, and indicate that the process of accommodating them is one of relationship building. For example, making room/space and leaving a gap open is not a literal activity, but the metaphoric act of including an otherwise socially excluded child. Metaphoric though it is, it operates through an instructional strategy- group work-that permits the student to participate meaningfully in class activity. This process positions the dean, and by extension the school, as caring. It is significant to note too that the meronyms help the speaker define his actions as planned and considered, so that accommodation is understood as deliberate policy. Two cultivation metaphors ("work on a person" and "space is made") also help achieve this. The active verbs in each, namely working and making space, imply pastoral efforts that are deliberate, planned, and goal-driven rather than serendipitous. In effect, they define the school as being in control and knowing what it is doing.

The speaker further positions himself as interested in students' welfare when, in lines 56-59, he uses the genre of a sales pitch to describe his approach to "selling" students the idea of the necessity of education (given what he had said earlier about their reluctance to attend school). This genre is signaled by the statement, "That is a line I always use and they love it.” He begins with the proposition that students may think that their "low condition" (presumably their social class) excludes them from the benefits of education. Then he constructs the sales pitch by focusing on his illocutionary intention: to have students arrive at the realization that education is important. His construction of this process focuses on (a) his method of communicating with "problem" students and (b) the effect of his efforts. In terms of method, the Dean constitutes himself as an advisor/counselor by using a series of verbs that emphasize 'telling' or lecturing about his experiences ("when they are told about other people's experiences.” "I go into my own personal experiences." "I tell them about things..” and "I tell them what..."). The force of these verbs is to position the teacher as an authoritative figure who, based on his experiences, has valuable information to transmit.

In terms of effect of his efforts, he says he shocks students with revelations from his biography. These are captured in the following phrases: "students are shocked", "their mouths open wide", and "they sit looking at me". He intends his utterances to have this illocutionary effect because he wants the audience to believe in the possibility of social mobility as a means out of their "low condition". In describing his final illocutionary intention- to have his audience believe (realize) "that there is somebody who cares"-the speaker overtly positions himself as caring and child-centered through his lexical choices, such as 'like' and 'love' and the phrase “means something to them”. 
That is, the verbs convey his attempt to advance his claims that he has succeeded in making students sense and be aware of his caring. Then he extends the claim even further when he posits a correlation between these actions on the one hand and physiological processes on the other ("They relax, they are comfortable, they try their best."). Through these means, the speaker manages both to define education as worthwhile and attainable for his students and to discursively position himself as a caring person, who is desirous of having students experience educational success.

In contrast, the lexical items associated with students' home backgrounds are all negative: "sent forcefully"," the care is not visible", "back into their house", "house environment”, “embarrassment”, “disrespect”, “cussing”, and "neglect”. These lexical choices position deviant students' homes as lacking in nurture. The specific use of neglect, for example, carries with it the connotation of child neglect and not merely the synonymy of forget or overlook. Here, neglect has the stronger sense of abandon and ignore. Thus, the speaker appears to be arguing not only that children learn the social, interpersonal value of disrespect in settling disputes, but, more poignantly, they learn that they are not very important to an angry parent, hence the deliberate use of neglect. In turn, this proposition links with the twice-repeated phrase "what they live" to signal just how deep-rooted is the nature of children's perspectives on the world: since this is their lived experience, it constitutes the only reality they know. The parents are thought to acculturate their children into mores that are unacceptable to the school. The image that emerges is one of dysfunctional parenting (Domitrovich \& Bierman 2001) causing anti-social attitudes and behavior. When these lexical choices are coupled with images of school as relatively impotent to counteract home influence the effect is significantly negative. For example, the dean positions the school as a mismatched pugilist when he says it is "outweighed" and the staff are "putting up a struggle" in a "hope against hope" but that "there is so much you could do". The combination of discursive choices in this text has several consequences for the narrative: 1. By positioning students in this deterministic way it removes agency from them: it emphasizes their status as victims, promotes the caring role of school, but avoids exploring whether students from these backgrounds have choice in their response to their environment, and 2. It establishes the speaker as caring for deviant children's welfare, yet realistic about the extent to which school can change their lives.

\subsection{Text 2. Interview with the principal}

1. I: In terms of disruptive behaviour, attitude to work and interpersonal relations, what is your

2. impression of students at this school?

3. R: Um..Let me be frank. I would say that the children are not improving. And we are talking 4.about attitude. Sometimes...we can come to the conclusion that free education may not be a

5. good thing. I have realised that the said child who might not have done well in this school.

6. When that child goes to a private institution and has to pay, the child performs better. So

7. sometimes free education may have its drawbacks, you know. Um, but I would say, all in all,

8. that um, society's changing and we have to cope with the problems. And you see, one has to

9. keep in mind also, um, ...that children tend to take cues from people with.. at a higher level

10. and sometimes they will make remarks, "Well if politicians can behave like this, why you

11. can't behave like that?"and then I would tell them, "No that's not the way to go.” So all these

12. things are..but, children in senior comprehensive, it's not easy to deal with, you know.

13. I: What is their discipline like?

14. R: Um, we have a larger group here to discipline than before, a larger group. Um, this takes a 
15. lot from people, as you know. Sometimes, teachers give up easily and say, “God, I’m fed up. 16. I'm tired and so on." The discipline in this school has not improved. This is solely because 17. the Ministry (of Education) is sending more and more students here. Two thousand children 18. not easy to cope with in an institution, you know. This is one of the reasons why they are 19. going to give me more deans in this institution, from seven they have moved to eleven.

20. I: How do you deal with what's happening?

21. R: Well, I try. I always feel somehow or the other that, um, you can give the..send out the 22. olive branch for the child to see if they can change. Make them..get them nearer to you.

23. Those who are giving problems, bring them nearer to you. In fact, the case I had just now, I 24. was willing to forgive that child already, you understand. Because she said to the teacher, 25. "Well, I know I have been rude." And I think this is my little strength there: When I can get 26. these children to tell them (teachers) that they have done something wrong and for the child to

27. admit he or she has done something wrong and to apologize to the teacher, you know. But I 28. am coping with the help of the teachers, the Deans and the Heads.

29. I: Do you think the teachers are satisfied? For example, if you had let the child apologize to 30. the teacher do you think the teacher would be happy with that?

31. R: No. Not completely. Not completely at all, but I would have... I try to convince the

32. teacher or teachers that you have to understand all the socio economic factors out there, you

33. know. And the background of the child, you know. That the child might have had problems

34. at home and sometimes parents cannot solve the problems and the problems come to the

35. school. So, no. All the teachers would not be satisfied, but at least I try my utmost to make 36. the teacher comfortable in the organization, you know.

37. I: How do you make a decision so that both parties get satisfaction?

38. R: ....I think this, um, over the years my experience alone, my experience can help me to

39. please both parties. I want to, I must prove to the teacher that the child knows and, in this

40. case, she has committed or has done something wrong: that she has been abusive to her. At

41. the same time, I want the teacher to feel comfortable by telling me, "Sir, I feel we should do

42. so by so." I'm not going to dismiss the teacher and say well look the child has forgiven you 43. (sic) and finish there. I want to strike a balance: for the teacher to feel satisfied and

44. comfortable in the organization. And what I do is I said, "Miss, I admire your courage." So I 45. also use props for the teacher to make the teacher stronger out there. You know I'm not going

46. to say, "Child just say something to the teacher" and that's it. I want the teacher to also make

47. an input to tell make how you feel about this.

48. I: How is it you don't hear about violence and weapon possession at this school?

49. R: All right. You do have violence in this school. You have cutlass play, you have knife

50. play, you have robbery and all kinds of things. But, what we try to do we try when we do

51. detect a case. We try to get the parents involved. We don't push the children away and say

52. we give up on you and throw you . away, and so on. We try to reason with the child. We

53. try to, um, we don't rush for the police right away. We try to get parents first. From parents,

54. we try to see where we can go. You understand. Um. You see. Again, I feel when I'm

55. dealing with children from the lowest stratum of society, I feel sometimes they don't know

56. what is right from what is wrong. Because in certain parts of this community

57. pulling...cursing is no big deal. Or, or quarrel with a cutlass. That is a kind of culture they

58. have and they don't see anything wrong with that. It is only when you bring the parents and

59. put them to sit and tell them that you realize well, no, no, my child has gone very far. Take,

60. for example, cursing. In some homes, you curse freely. It means nothing, you understand.

61. And when we get the parent involved they begin to understand; yeah, this is wrong. Whereas

62. some schools in the north, as soon as a child falls short that's the end of you and they try to 63. make a big issue out of the thing.

64. I: What do you think of suspension and expulsion?

65. R: No, I'm not in favor of that at all. I'm not in favor of suspending and expelling at 66. all. I'm in favor of trying to bring the parties together to see if you can solve or resolve the 67. problem. And you know, I think some of us, meaning some of the principals, we are too 
68. harsh. We don't take time to sit and listen to some of the problems the children have. It is a 69. fact the schools are huge, um, many principals try to solve the problem as quickly as they can.

70. Or, they will try to remove the problem by saying, "Go from here. Don't come back. That's 71. it." But, the problem is if it's not in the school it will be outside and I always believe...look I

72. took children from post primary schools and I put them in form four ${ }^{5}$. Those children did 73. pretty well in the tech. voc. areas. So one has to experiment also with some children. I always

74. believe, eh, that there will come a time when a child will realize, "You know, look at what I 75. have done, and you know, I'm sorry." I've heard many people say that many students say, "If

76. I had studied a little harder, eh. I would have been better off.” So there is room always for 77. improvement. A child may fall short and maybe the next six months or seven months the 78. child will say I'm sorry. That's what I see. My philosophy is never give up. Given the 79. opportunity, I believe some of these children will do well. If some of them had better 80. surroundings, who knows?

The following analysis of the interview with the principal divides the text into two movements or segments. In the first movement, the speaker is assessing reasons for the non-improvement of his school both academically and in terms of student discipline. The central device he uses in this movement is extreme formulation (Pomerantz 1986), when he says, "This is solely because the Ministry is sending more and more students here.” This permits him to focus all attention and place all blame on an external agency for engaging in a practice that makes it difficult for him to cope. Embedded within that statement is his correlation of rising enrolment with poor discipline, signaled through use of because. This in turn buttresses his declaration that it is not easy to cope with two thousand children at a school. The significant implication arising out of his extreme formulation is that if the student population were smaller it would be more manageable, there probably would be fewer incidents of indiscipline, and his staff would be less frustrated. This is an important consideration for him since frustrated and fed-up teachers apparently make demands for deviant students to be excluded from school (lines 14-32).

This then leads to the first instance of positioning by the principal: he locates himself in contraposition to his teachers. The principal's choice of two advocacy verbs, "convince" and "prove" ("I try to convince the teacher"; "I must prove to the teacher") implies that he occupies a philosophically different position to theirs. It also establishes him as inclusive and, like his dean, he positions himself as experienced and therefore entitled to treat with deviants more sympathetically and not exclude them. Furthermore, his main proposition in lines 21 to 28 is that he manages disciplinary issues by being conciliatory and making peace. He positions himself as subscribing to an inclusionary ideal by espousing the strategy of personalization (Shore 1996; Halford 1996). In this strategy, the authority figure, here the principal, but more commonly a classroom teacher, deliberately seeks out a child at risk for school failure and becomes his/her confidante. The adult engages in this kind of personalization, so that the student feels less anonymous amongst the entire student body. It is interesting that the first three sentences have two repairs ("give the..send out"; "Make them..get them") as the speaker tries to define his administrative style and strategy. The first is possibly an error in verb

\footnotetext{
${ }^{5}$ Form four is a class level catering to 15 year olds. Children from post-primary schools have low literacy rates and would be expected to struggle with content area literacy tasks. The principal's point is that he took a risk by mainstreaming the children and they did well.
} 
choice as he tries to get at the formulaic expression, "offering/extending an olive branch". In the second, he discards one causative verb (Jung Song 1996) for another apparently choosing a "softer", less coercive one. This is repeated in the next sentence, where he recommends bringing difficult students closer. Extending the metaphoric olive branch appears to be the main organizing idea in this movement. It works by amplifying the core idea through a small set of meronyms: "bring them nearer", "forgive that child", "my little strength", and "understand all the socioeconomic factors". These convey the notion of making peace with erring children. They stand in contrast to the terminal image conveyed in "that's the end of you", which is the principal's assessment of what occurs in other schools, and possibly what he thinks some of his own staff want him to do. This principal's first recourse, therefore, is one of inclusion based on belief in the possibility of adolescent change and development. In this respect, the meronyms have a similar purpose and effect to those of inclusion used by the dean.

In the second movement of the interview (lines 49-80), the principal directly addresses the phenomenon of low incidence of suspensions and expulsions. He argues that though incidents occur that should attract these penalties, yet the school's policies and its student management philosophy do not favor this approach. The principal deals with the issue as one of choice and positions himself as an inclusive educator. This is captured in his use of the phrase "never give up". This formulaic expression acts as a superordinate to organize the two major devices in this movement: 1.Contrast with other principals, and 2. Drawing of causal relationships between students' home background and their school behavior. The contrast (overtly signaled by 'whereas' in line 61) depends for its relevance and significance almost entirely upon the causal connections the principal makes. Between lines 55 and 58, the principal attempts to establish an unequivocal connection between the socialization practices of home and community on the one hand and students' inability to discriminate between right and wrong on the other. The because clause ("Because in certain parts of this community..") presents this as a social class connection: children from the "lowest stratum of society" are socialized into a culture of violence and swearing, so they do not recognize that what they are doing is wrong. Within the interview, the recognition of this causal connection acts as a justification for the principal's stated philosophy of inclusion. Through its use, he is able to position himself "philosophically" in opposition to principals of other schools.

Principals of some other schools are positioned (lines 51-52; 69-71) as exercising negative choices because they are interested only in expeditiously dismissing deviant students, in getting rid of them so that the business of the school can continue. This positioning is achieved through a series of contrasts. In speaking of exclusionary principals, the speaker uses the following phrases to characterize (and judge) their actions: "Push the children away", "throw you away", "make a big issue", "we are too harsh", "we don't take time", "try to remove the problem". In speaking of his own practices, he says, "we try to reason", "get parents first", "bring the parties together", "resolve the problem". These lexical choices present the principal as interested in fixing the problem over the long term as opposed to moving it elsewhere. Furthermore, the "philosophical" basis for his position is elaborated in the last seven lines of the interview (lines 74 -80), where the recurrence of modal will emphasizes his belief in the possibility of children's development. His core argument is that even the most erring adolescent will realize his errors and eventually "do well”.

At the very end of the interview, the principal uses the formulaic "never give up" to express his optimistic stance with respect to children from the "lowest stratum of 
society”. Although it appears at the end, it seems to function as a superordinate in managing the contrast between a decision maker (the speaker) who chooses to retain faith in deviant students and keep them close on the one hand, and other school principals on the other hand who are less accommodating, and (presumably) give up. Finally, the formulaic expression links to the causal connection ("Because in certain parts of this community.."): it is because the principal occupies the position of not giving up that he willingly works with deviant students, whose home values differ from those of the school's, and rejects the option of suspending them. The overall effect is to present the speaker as a caring, understanding, and inclusive educator.

\subsection{A note on causal connections}

In the two texts presented here, the causality marker because shouldered all the work of conveying speakers' attempts to make correlations. The major correlations they drew were between students' backgrounds on the one hand and their engagement in deviant acts on the other. Previous scholarly analyses of the function of because indicate that it is a strong causative. For example, in their analysis of a corpus of tobacco industry documents, Brown and Rubin 2005 showed that the causality markers because, since, and as "convey or deflect responsibility more or less strongly" (p. 799) depending on which one initiates the clause. The adjunct because was described as considerably stronger at the task of making explicit causal links or associations between co-variables (here use of tobacco co-varied with incidence of cancer) than use of since and as, which are disjuncts. Given the finding that choice of causal marker determines the strength of the causative association a speaker/writer wants to create between co-variables, it is interesting to note that in the two interviews treated here there are no uses of since, and no instances of the use of as as a disjunctive causal marker. The burden of conveying causal relations falls entirely upon because. Where it is used to describe negative effects of suspension (by the dean), the causal relations created are between suspension of students on the one hand and their retreat into a metaphoric cave on the other. This suggests that the aftermath of punitive action produces personally undesirable antisocial results, so sending home such a student is unproductive, even harmful.

\section{Creating a caring identity}

The major discourse realized in both speakers' narratives is one of caring. Both speakers position themselves as providers of care to "needy" school populations, where they define that need in terms of "deficient" family backgrounds. The construction of their positions as caring, inclusive administrators suggests that they appropriated and are participating in larger profession-based Discourse. Like the field of nursing, teaching has traditionally been conceptualized as a caring occupation and vocation. Goldstein \& Freedman (2003) quote Kohl's (1984) declaration, “A teacher has an obligation to care for every student" as an example of what they believe to be the popular perception that caring is a central tenet of teaching. Cortis \& Kendrick (2003: 78) define caring as follows: "Care can be described as an attitude or orientation that leads to the beneficent attending, through acts or omissions, of one person towards another". Core to their definition are the notions of caring as affective, inclusive, interpersonally dynamic, 
therapeutic and having a moral imperative. Although these characteristics pertain to nurses as constructed in the professional literature on nursing, and they construct it as a virtue (Van Hooft 2003 quoted by Gustafsson, Asp \& Fagerberg 2009), it is not materially different from the model of education proposed by Noddings (1992). For her,

When we discuss teaching and teacher-learner relationships in depth we will see that teachers not only have to create caring relations in which they are the carers, but that they have a responsibility to help their students develop the capacity to care. (Noddings 1992: 18)

Noddings' (1992) work has had a profound influence on teacher education by sparking a re-orientation of what is "important" in teachers' work. One of her principal arguments has been that teachers need to act towards students in such a way that, "Students should be aware that their schools are conceived as centers of care..." (1992: 65). Such a philosophy overtly positions students as receivers of care, schools as places where care is offered, and teachers as care-providers. Recently, too, Søreide's (2006: 536) interviews with female Norwegian teachers' revealed that they constructed four main identities: 'the caring and kind teacher'; 'the creative and innovative teacher'; 'the professional teacher', and 'the typical teacher'. Interviewees who identified themselves as caring and kind placed emphasis on feeling closeness to children, having responsibility for their well-being and development, and providing a safe social environment for their growth. The two male administrators interviewed for the present study essentially espoused the same philosophy and, since they were in decision-making positions at their school, were able to translate that inclusive attitude into actual policy. In effect, the caring identity realized through talk in the interviews was congruent with the administrative non-implementation of zero tolerance for deviant acts generally practiced at the school. This caring identity is discursively created by each speaker despite their somewhat differing attitudes to what they believe will be the consequences of their caring: unlike the dean, who positions students' homes as overwhelming and says "there is so much you could do", the principal acknowledges such constraints, but says he will never give up. This suggests that perhaps the broad rubric, "caring", accommodates degrees of administrator efficacy in dealing with deviant students, who are ostensibly in need of care.

\section{Conclusion}

The foregoing analysis of two school administrators' discourses on the subject of adolescent deviance argued that they engaged in positioning themselves as inclusionary and caring. They positioned deviant students as victims of overpoweringly negative environments and, to a lesser extent, positioned their institution as a warm and welcoming space. Their basic contention in accounting for their hesitation to exclude students, and instead to pursue inclusionary policies, was that deviant students could not escape their primary socialization, and that they-the school administrators- had to meet this challenge by extending caring. To care then meant to include and assume some responsibility for troubled adolescents.

Within the literature on teacher education, performing a caring identity is a cornerstone of responsive pedagogy. Teacher trainees leave training programs knowing 
that caring for students is the dominant discourse. The interviewees in this study claimed membership in the category "caring teacher", and positioned themselves within that category by drawing causal connections and making lexical choices that showed them actively engaging in caring. They constituted the category by arguing that they were doing caring, verbalizing caring, and being caring. Such a discursive position is a demonstration of being in consonance with dominant discourses in one's field. That is, it shows administrators observing best practices. It also accomplishes a subtler discursive task: it positions this pair of decision-makers as pro-active and decisive.

In conclusion, the data presented in the present study suggests that in describing their experiences with deviant students and attempting to account for their inclusionary administrative decisions, the two school administrators equated caring with professional competence. Just as importantly, they managed to humanize deviant students by positioning them as requiring care.

\section{References}

Atkins, M.S., M.M. McKay, S.L. Frazier, L.J. Jakobsons, P. Arvanitis, T. Cunningham, C. Brown, and L. Lambrecht (2002) Suspensions and detentions in an urban, low-income school: Punishment or reward? Journal of Abnormal Child Psychology 30.4: 361-371.

Brown, C., and D.L. Rubin (2005) Causal markers in tobacco industry documents: The pragmatics of responsibility. Journal of Pragmatics 37: 799-811.

Christle, C.C., M. Nelson, and K. Jolivette (2004) School characteristics related to the use of suspension. Education \& Treatment of Children 27: 509-526.

Cortis, J.D., and K. Kendrick (2003) Nursing ethics, caring and culture. Nursing Ethics 10.1: 77-88.

Cullingford, C. (1999) The causes of exclusion. Home, school, and the development of young criminals. London: Kogan Page.

Currie, D.H., D. Kelly, and S. Pomerantz (2007) Listening to girls: Discursive positioning and the construction of self. International Journal of Qualitative Studies in Education 20.5: 377-400.

Davies, B., and R. Harré (1999) Positioning and personhood. In R. Harré \& L. Van Langenhove (eds.), Positioning theory. Oxford: Blackwell, pp.32-52.

DeWit, D.J., D.R. Offord, M. Sanford, B.J. Rye, M. Shain, and R. Wright (2000) The effect of school culture on adolescent behavior problems: Self esteem, attachment to learning, and peer approval of deviance as mediating mechanisms. Canadian Journal of School Psychology 16.1: 15-38.

Dodge, K.A., T.J. Dishion, and J.E. Lansford (2006) Deviant peer influences in intervention and public policy for youth. Social Policy Report XX. 1: 3-19. Available from http://www.srcd.org/spr.html

Domitrovich, C.E., and K.L. Bierman (2001) Parenting practices and child social adjustment: Multiple pathways of influence. Merrill-Palmer Quarterly 47: 235-263.

Fairclough, N. (2001) Language and power ( $2^{\text {nd }}$ ed.). Essex, UK: Pearson Education.

Fontana, A., and J.H. Frey (2005) The interview. From neutral stance to political involvement. In N.K. Denzin \& J.P. Gee, (1999) An introduction to discourse analysis. Theory and method. London: Routledge. 
Goldstein, L.S., and D. Freedman. (2003) Challenges enacting caring teacher education Journal of Teacher Education 54.5: 441-454.

Gustafsson, C., M. Asp, and I. Fagerberg (2009) Municipal night nurses' experience of the meaning of caring. Nursing Ethics 16.5: 599-612.

Halford, J.M. (1996) Policies for safety, caring, and achievement. InfoBrief, 6. Retrieved July 2009 from http://www.ascd.org/portal/site/ascd/menuitem.c30040c1b9063eeeb85516f762108a0c/

Heckert, A., and D. Heckert (2002) A new typology of deviance: Integrating normative and reactivist definitions of deviance. Deviant Behavior 23.5: 449-479.

Jung Song, J. (1996) Causatives and causation. A universal typological perspective. London: Longman.

Noddings, N. (1991) The challenge to care in schools. An alternative approach to education. NY: Teachers College Press.

Poggenpoel, M., N. Van Der Linde, and L. Zeeman (2002) An introduction to a postmodern approach to educational research: Discourse analysis. Education 123.1: 96-103. Retrieved June 14, 2005, from Questia.com database.

Pomerantz, A. (1973) Extreme case formulations: A new way of legitimating claims. In G. Burton, P. Drew, \& J. Heritage (eds.) Human Studies (Interaction and Language Use special issue) 9: 219-30.

Reid, K. (2008)National attendance and behaviour review (NBAR) . Department for children, education, lifelong learning and skills. Accessed November 8, 2009 from

http://wales.gov.uk/topics/educationandskills/publications/guidance/nbarsummaryactionplan/;jsessionid= gLY7KXVXKzWGH0W0npdFnlQwyGjn8crKVvY1GdmWJRbl5lm242rn!-692465818?lang=en

Rosenthal, B.S., and W.C.Wilson (2003) The association of ecological variables and psychological distress with exposure to community violence among adolescents. Adolescence 38.151: 459-479.

Shore, R.M. (1996) Personalization: Working to curb violence in an American high school. The Phi Delta Kappan 77.5: 362-363.

Sims, J., R. Bowen, and D. Holtom (2008) Rapid evidence assessment of the interventions that attempt to improve behaviour and attendance in schools and other learning settings. Abergavenny, Monmouthshire, UK: People and work unit. Retrieved November 2009 from

http://newydd.cymru.gov.uk/topics/educationandskills/educationskillsnews/2233523/;jsessionid=9QtJK7

TKxPfzJGks57vswMsKKqTJRndtZ7s1zdQ7TsK5VnGzYhvc!-973892656?cr=3\&lang=en

Søreide, G.E. (2006) Narrative construction of teacher identity: Positioning and negotiation. Teachers and Teaching: Theory and Practice 12.5: 527-547.

Townsend, B.L. (2000) The disproportionate discipline of African American learners: Reducing school suspensions and expulsions. Exceptional Children 66.3: 381-391.

Trinidad and Tobago. Ministry of Education. (2002). SEMP baseline survey 2002. Port of Spain, Trinidad.

Wood, L.A., and R. Kroger (2000) Doing discourse analysis. Methods for studying action in talk and text. Thousand Oaks, California: Sage.

Youngstrom, E., M.D. Weist, and K.E Albus (2003) Exploring violence exposure, stress protective factors and behavioral problems among inner-city youth. American Journal of Community Psychology 32: 115-129. 


\section{Krishna Seunarinesingh}

KRISHNA SEUNARINESINGH (Ph.D. in Education) is a lecturer in teacher education at The University of the West Indies, St. Augustine, Trinidad and Tobago. His research interests span the areas of educational pragmatics, teaching elementary school language arts, and adolescent literacy in each of which he has published articles in scholarly journals. He has a special interest in issues of student marginalization and student violence and how these are discursively constructed in schools.

Address: School of Education, The University of the West Indies, St. Augustine, Trinidad and Tobago. Email: krishna.seunarinesingh@sta.uwi.edu 